\title{
Epidemiology of Intravitreal Injections in Iran: Indications and Referral Patterns in a Tertiary Hospital
}

This article was published in the following Dove Press journal:

Clinical Ophthalmology

\section{Mohammad Zarei (D' \\ Ramak Roohipoor (iD) \\ Raziyeh Mahmoudzadeh (iD) \\ Mehdi Yaseri iD ${ }^{2}$ \\ Hamid Riazi-Esfahani (D) \\ 'Retina Service, Farabi Eye Hospital, Tehran University of Medical Sciences, \\ Tehran, Iran; ${ }^{2}$ Department of \\ Epidemiology and Biostatistics, School of Public Health, Tehran University of \\ Medical Sciences, Tehran, Iran}

Correspondence: Hamid Riazi-Esfahani Retina Service, Farabi Eye Hospital, Tehran University of Medical Sciences, Qazvin Square, South Kargar Street, Tehran I3366I635I, Iran

Tel +98 9123779108

Email Hamidriazi@gmail.com
Purpose: To study the relative contribution of major indications and geographic referral patterns for intravitreal bevacizumab injections in a tertiary hospital.

Methods: In this retrospective study, hospital electronic registry was used to categorize patients who had received intravitreal injections (IVIs) during the 2014-2016 period into different groups based on indications. Relative contribution of each indication and odds of being resident of provinces other than Tehran were determined.

Results: The most prevalent indications for IVI were pathologies related to diabetes mellitus (DM) followed by choroidal neovascularization (CNV)/age-related macular degeneration (AMD) and retinal venous occlusion (RVO)-related complications. From 38,043 patients, $61.8 \%$ were residents of Tehran province. Patients in the CNV/AMD group were the oldest. Patients from Tehran province were significantly older $(62.44 \pm 11.42$ (12-99)) than patients who were referred from other provinces $(59.23 \pm 11.39(11-102))(\mathrm{p}=<0.001)$. The majority of patients in all indication categories were from Tehran province, except for patients with retinopathy of prematurity (ROP). Odds of being referred from outside Tehran province for the ROP group compared to the DM-related, CNV/AMD, RVO-related and miscellaneous groups were $3.32,4.27,3.13$ and 2.83 , respectively $(\mathrm{p}<0.001)$.

Conclusion: DM-related ocular complications outnumber all other indications of IVIs combined. Considering the preventable nature of these complications, efficient health policies can significantly reduce the burden of IVIs in Iran. The contribution of each indication category in overall burden of IVIs seems to vary considerably between different countries which merits further studies. The disproportionately high ratio of ROP patients who are referred from other provinces to the capital province for treatment indicates a suboptimal distribution of ROP care services throughout the country.

Keywords: epidemiology, indications, intravitreal injection, diabetes, retinopathy of prematurity, referral patterns

\section{Introduction}

Intravitreal injection (IVI) of anti-VEGF agents was first proposed as a novel treatment for neovascular age-related macular degeneration (AMD) in the early years of twenty-first century. ${ }^{1,2}$

Since then, multiple agents have been introduced and indications have expanded to some of the most common ocular diseases, including diabetic eye disease, retinal vascular occlusive diseases, choroidal neovascularization (CNV) caused by various conditions, and retinopathy of prematurity (ROP). ${ }^{3-5}$ Although the development of 
these drugs has revolutionized the management of retinal disorders, it also has brought some unprecedented challenges. Most conditions which are currently treated by these agents are of chronic nature and the fact that these drugs usually have transient therapeutic effects, means that most patients need frequent clinical visits, imaging procedures, and repeated IVIs. This situation obviously imposes a huge burden on health-care systems, especially in countries with lower per capita income. Another relevant issue in these countries is the suboptimal nationwide distribution of health-care services which raises the costs and jeopardizes the availability of optimal care for all patients.

Iran is a developing country with a population of 80 , 277,430 according to 2016 census which is unevenly distributed over its various geographic regions. ${ }^{6}$ Recent censuses predict that its population is getting progressively older and the prevalence of chronic age-related ocular diseases is expected to increase in the future. Among these are diabetic ocular complications, retinal occlusive vascular diseases and age-related macular degeneration which are currently treated by repeated IVIs. Therefore, it seems necessary to have a clear picture of relative contribution of each disease in the overall burden of IVIs to guide further epidemiologic interventions and foresee required resources in coming years.

Farabi Eye Hospital in Tehran is the largest eye care center in Iran. A large subset of patients treated in this hospital is referred from outside the Tehran province. By studying the referral pattern of patients who have received intravitreal injections we tried to obtain relevant information about the current distribution of eye care services throughout the country. This may highlight weak points that should be addressed by health policymakers.

A survey by the American Society of Retinal Specialists in 2014 showed that bevacizumab and ranibizumab were the most common anti-VEGF drugs used in the US and EU, respectively. ${ }^{7}$ Considering the lower cost, intravitreal bevacizumab is especially popular in developing countries including Iran. In this work, we used the electronically registered information of patients who have received IVI in a tertiary hospital in Iran to study the relative contribution of each indication and geographic referral patterns.

\section{Subjects and Methods}

This non-interventional, retrospective study was conducted in Farabi Eye Hospital, Tehran, Iran. The ethical board committee of Tehran University of Medical Sciences approved the study protocol. Tenets of the Declaration of Helsinki were followed.

Hospital electronic registry of patients receiving intravitreal injections (IVIs) between September 2014 and November 2016 was used as the source of information. This registry included the names and surnames of all patients, reception number (unique to each patient), birth date, birthplace, city of residence, address, injection date, and the diagnostic code. The gender of patients was not recorded.

Due to temporary changes in the hospital regulations, the diagnostic codes (indication for IVI) were not electronically registered in a 5.5-month interval during the study period.

Patients were categorized into 5 groups based on the indication of IVI: 1) diabetes mellitus (DM)-related indications, 2) CNV/AMD-related indications, 3) retinal venous occlusion (RVO)-related indications, 4) ROP, and 5) miscellaneous indications. According to the province of residence, patients in each diagnostic category were grouped into two subsets: 1) residents of Tehran province and 2) residents of other provinces. Demographic data of each group were documented.

The primary outcome of the study was the relative contribution of each indication category in total study population and the secondary outcome was the odds of being resident of provinces other than Tehran.

\section{Statistical Analysis}

To present data, we used mean and standard deviation, median and range, frequency and percentage. Comparisons between the groups performed by ChiSquare and Analysis of Variance (ANOVA). To obtain the Odds Ratio (OR) we used Binary and Multinomial logistics regression, whenever appropriate. All Statistical analysis performed by SPSS software (IBM Corp. Released 2015. IBM SPSS Statistics for Windows, Version 24.0. Armonk, NY: IBM Corp.). A P value less than 0.05 was considered statistically significant.

\section{Results}

Between September 2014 and November 2016, a total number of 38165 operation room visits for IVI were recorded. The city of residence for 38043 patients and an indication for treatment of 31588 patients were documented. Among the five indication categories, most prevalent was DMrelated $(n=19,871)$, followed by CNV/AMD $(n=5010)$, RVO-related $(\mathrm{n}=4649)$, miscellaneous $(\mathrm{n}=1709)$, and ROP 
Table I Number of Patients Receiving IVI in Each Indication Category

\begin{tabular}{|l|l|}
\hline Indication Category & Number of Injections (Percentage) \\
\hline DM-related & $19,871(62.9 \%)$ \\
CNVIAMD & $5010(15.8 \%)$ \\
RVO-related & $4649(14.7 \%)$ \\
ROP & $349(1.1 \%)$ \\
Miscellaneous & $1709(5.4 \%)$ \\
\hline
\end{tabular}

Abbreviations: DM, diabetes mellitus, CNV, choroidal neovascularization, AMD, age-related macular degeneration, RVO, retinal venous occlusion, ROP, retinopathy of prematurity.

$(\mathrm{n}=349)$ (Table 1). From 38,043 patients 23,518 (61.8\%) were from Tehran province and the remaining were from outside Tehran province.

The mean age of patients (excluding ROP patients) was $61.28 \pm 11.50$ y (11-102 years old). Table 2 shows the mean age of patients in each indication category (excluding ROP). There was a significant age difference between different indication categories $(\mathrm{p}=<0.001$; ANOVA $)$. Patients in the CNV/AMD group were the oldest and patients in the miscellaneous group were the youngest. Comparison of mean age between indication categories showed that the age difference for each comparison was statistically significant (Table 3). Patients from Tehran province were significantly older (62.44 \pm 11.42 (12-99) years) than patients who were from other provinces $(59.23$ \pm 11.39 (11-102) years) ( $\mathrm{p}=<0.001$, one-way ANOVA).

The majority of patients in all indication categories other than ROP were from Tehran province $(61.4 \%$, $67.2 \%, 60 \%$ and $57.4 \%$ for DM-related, CNV/AMD, RVO-related and miscellaneous groups, respectively). In the ROP group, the majority of patients (236 from 349 patients, 67.4\%) were from outside of Tehran province (Table 4). Odds of being referred from outside of Tehran province for the ROP group compared to the DM-related,

Table 2 Mean Age in Each Indication Category and in Total Study Population (Excluding ROP)

\begin{tabular}{|l|l|l|l|l|}
\hline & Mean & $\begin{array}{l}\text { Standard } \\
\text { Deviation }\end{array}$ & Minimum & Maximum \\
\hline DM-related & 59.6557 & 10.10152 & 13.00 & 102.00 \\
CNV/AMD & 69.0531 & 12.21884 & 19.00 & 97.00 \\
RVO-related & 60.8055 & 12.52894 & 14.00 & 97.00 \\
Miscellaneous & 58.6928 & 12.35638 & 11.00 & 99.00 \\
Total & 61.2813 & 11.50303 & 11.00 & 102.00 \\
\hline
\end{tabular}

Abbreviations: DM, diabetes mellitus; CNV, choroidal neovascularization; AMD, age-related macular degeneration; RVO, retinal venous occlusion.
Table 3 Age Difference (Years) Between Indication Categories (Excluding ROP)

\begin{tabular}{|l|l|l|l|}
\hline $\begin{array}{l}\text { First } \\
\text { Indication } \\
\text { Category }\end{array}$ & $\begin{array}{l}\text { Second } \\
\text { Indication } \\
\text { Category }\end{array}$ & $\begin{array}{l}\text { Mean Age } \\
\text { Difference Between } \\
\text { First and Second } \\
\text { Indication } \\
\text { Categories }\end{array}$ & P value* \\
\hline DM-related & $\begin{array}{l}\text { CNV/AMD } \\
\text { RVO-related } \\
\text { Miscellaneous }\end{array}$ & $\begin{array}{l}-9.39736 \\
-1.14982 \\
0.96293\end{array}$ & $\begin{array}{l}<0.001 \\
<0.001 \\
0.003\end{array}$ \\
\hline CNV/AMD & $\begin{array}{l}\text { RVO-related } \\
\text { Miscellaneous }\end{array}$ & $\begin{array}{l}8.24754 \\
10.36029\end{array}$ & $\begin{array}{l}<0.001 \\
<0.001\end{array}$ \\
\hline RVO-related & Miscellaneous & 2.11275 & $<0.001$ \\
\hline
\end{tabular}

Notes: *Based on ANOVA, multiple comparisons are performed by Bonferroni method.

Abbreviations: ROP, retinopathy of prematurity; DM, diabetes mellitus; CNV, choroidal neovascularization; AMD, age-related macular degeneration; RVO, retinal venous occlusion.

Table 4 Ratio of Tehran and Non-Tehran Residents in Each Indication Category

\begin{tabular}{|l|l|l|}
\hline $\begin{array}{l}\text { Indication } \\
\text { Category }\end{array}$ & $\begin{array}{l}\text { Province of } \\
\text { Residence }\end{array}$ & $\begin{array}{l}\text { Number } \\
\text { (Percentage) }\end{array}$ \\
\hline DM-related & $\begin{array}{l}\text { Tehran } \\
\text { Others }\end{array}$ & $\begin{array}{l}12,210(61.4 \%) \\
7661(38.6 \%)\end{array}$ \\
\hline CNVIAMD & Tehran & $3366(67.2 \%)$ \\
& Others & $1644(32.8 \%)$ \\
\hline RVO-related & Tehran & $2789(60.0 \%)$ \\
& Others & $1860(40.0 \%)$ \\
\hline ROP & Tehran & $113(32.4 \%)$ \\
& Others & $236(67.6 \%)$ \\
\hline Miscellaneous & Tehran & $984(57.6 \%)$ \\
& Others & $725(42.4 \%)$ \\
\hline All indications & Tehran & $19,462(61.6 \%)$ \\
& Others & $12,126(38.4 \%)$ \\
\hline
\end{tabular}

Abbreviations: DM, diabetes mellitus; CNV, choroidal neovascularization; AMD, age-related macular degeneration; RVO, retinal venous occlusion; ROP, retinopathy of prematurity.

CNV/AMD, RVO-related and miscellaneous groups were $3.32,4.27,3.13$ and 2.83 , respectively $(\mathrm{p}<0.001)$ (Table 5).

\section{Discussion}

This study retrospectively evaluates data from the Farabi Eye Hospital patient registry, which is a tertiary eye center in Tehran. The objective was to obtain insight into realworld treatment patterns of intravitreal injections; more specifically, the relative contribution of major eye diseases 
Table 5 Odds of Being Referred from Outside of Tehran Province in ROP Patients Compared to Other Indication Categories

\begin{tabular}{|l|l|l|l|}
\hline $\begin{array}{l}\text { Compared } \\
\text { Categories }\end{array}$ & $\begin{array}{l}\text { Odds of Being } \\
\text { Referred from } \\
\text { Outside Tehran }\end{array}$ & $\begin{array}{l}\mathbf{9 5 \%} \\
\text { Confidence } \\
\text { Interval }\end{array}$ & P value* \\
\hline ROP:DM-related & 3.32 & $2.65-4.17$ & $<0.001$ \\
ROP: CNV/AMD & 4.27 & $3.39-5.39$ & $<0.001$ \\
ROP: RVO-related & 3.13 & $2.48-3.94$ & $<0.001$ \\
ROP: Miscellaneous & 2.83 & $2.22-3.61$ & $<0.001$ \\
\hline
\end{tabular}

Note: *Multinomial logistic regression.

Abbreviations: ROP, retinopathy of prematurity; DM, diabetes mellitus; CNV, choroidal neovascularization; AMD, age-related macular degeneration; RVO, retinal venous occlusion.

to the total burden of IVIs and referral pattern of patients from provinces other than Tehran.

In our study, the vast majority of patients receiving IVIs $(62.9 \%)$ were treated for DM-related indications $(n=19,871)$. It is in contrast to Vorum et al who found neovascular AMD (nAMD) as the most common indication in 19,522 IVIs during a 3.5-year period in Denmark. ${ }^{8}$ In their study, diabetic macular edema $(6.2 \%)$ was ranked third after nAMD (54.3\%) and RVO (8.2\%). ${ }^{8}$

Similarly, Bavinger et al, reported that from 1,095,305 IVIs performed in a 11-year period in the United States, $\mathrm{AMD} / \mathrm{CNV}$ was the most frequent indication (52.9\%), followed by diabetic retinopathy (11.8\%), and vein occlusion/ CME (cystoid macular edema) (9.9\%). ${ }^{9}$ More similar to our results, in a small study, Shuaib and Hassan reported that in 174 IVIs in north western Nigeria, DME and proliferative diabetic retinopathy were the most common indications (44.8\%), followed by RVO (25.8\%) and AMD/CNV $(8.6 \%){ }^{10}$ There may be at least two explanations for this discrepancy. First, this may reflect suboptimal medical care for diabetes in Iranian patients with subsequent more common occurrence of related ocular complications compared to Danish or the United States population. It is well known that lifestyle habits influence greatly on incidence of DM. ${ }^{11}$ There is also strong evidence that preventive measures and therapeutic interventions can reduce the incidence of microvascular complications of DM including ocular complications. ${ }^{12}$ Lifestyle modifications and medical interventions are probably more effective in the prevention of DM-related IVIs compared to AMD-related IVIs. This evidence collectively suggests that by promoting preventive health policies and educational programs, focused on lifestyle changes, improvement of screening programs, and optimizing therapeutic interventions it is possible to decrease the DM-related ocular complications in Iran which can mitigate the burden of IVIs significantly in future.

The second possible reason for the different patterns observed in these studies is the older population of developed countries compared to developing countries which can be responsible for the higher prevalence of AMD. ${ }^{13,14}$ We found that patients in CNV/AMD category, were almost 10 years older than DM-related category, which highlights the role of aging in the development of nAMD. According to national censuses, the Iranian population is getting older, so it is plausible to expect that the vast difference between DM-related indications (62.9\%) and CNV/AMD indications (15.8\%) observed in our study, may change in coming years. This possible trend should also be considered in any interpretation of changes in results of future similar studies. ${ }^{14}$

As expected, the majority of patients $(19,462$ patients $(61.6 \%))$ were Tehran residents. This pattern was seen in all categories but the ROP category, in which most patients $(67.6 \%)$ were from provinces other than Tehran. This reversal of referral pattern in the ROP category indicates that compared to resources allocated to the management of other categories, in a nationwide level the resources for the management of ROP have a suboptimal distribution. Although regional differences in birth rate and premature birth rate may cause differences in incidences of ROP in various regions of the country, the magnitude of this reversal of referral pattern in the ROP category is so large that it possibly warrants considering additional factors. ${ }^{15}$ Although the availability of health-care services for ROP patients has not yet been studied specifically in Iran, this may reflect a combination of obstacles that encourage the physicians to refer ROP patients to Tehran instead of managing them in nearby centers. These obstacles may include lack of adequate health-care providers specifically trained in the management of premature neonates including ROP patients, suboptimal distribution of skilled ophthalmologists at a national scale, and ethical and medicolegal issues concerning the heavy consequences of inadvertent mismanagement of these patients. ${ }^{16}$ It is noteworthy that due to persistent avascular area, ROP patients treated with intravitreal anti-VEGFs, need frequent visits and longer follow-ups periods compared to ROP patients treated with laser, so the high rate of referrals of these vulnerable patients to a distant center imposes a large burden on families and health-care system. ${ }^{17}$ Therefore, it is pertinent to take measures to reduce these referrals. Some suggestions are training ophthalmologists and other health service staff specifically for ROP management, providing 
more centers with equipment necessary for the management of premature neonates, implementing telemedicine technology, strengthening supportive network for practicing ophthalmologist in other centers, and considering financial and non-financial incentives to encourage management of ROP patients rather than referring them.

Our study showed that patients from Tehran province were significantly older than patients who were referred from other provinces (Table 4). We also found that compared to other categories, Tehran: non-Tehran resident ratio was the highest in CNV/AMD categories (Table 5). The fact that mean age of the population of Tehran province is higher than mean national age can partly explain this finding. ${ }^{18}$ Moreover, transportation difficulties for elderly patients may prevent the older non-Tehran residents coming to Tehran. We do not have adequate data to further clarify the relative contribution of each of these two factors.

The possibility of data entry errors cannot be entirely ruled out, but the large study population may mitigate the confounding effect of such errors. Another limitation is that due to lack of registry of some potentially relevant variables like gender and socioeconomic status which have epidemiologic implications, our evaluation of factors affecting referral pattern is not complete.

\section{Conclusion}

Our findings suggest that the relative contribution of major indications of IVIs can be considerably different in various populations with different demographic and socioeconomic characteristics. This indicates that to reduce the increasing burden of IVIs in the most efficient way, population-specific strategies should be considered. Namely, in our study, DM-related ocular complications outnumber all other indications of IVIs combined and considering the preventable nature of these complications, we suggest that the burden of IVIs can be reduced significantly by better prevention and management of diabetes. Obviously, more studies are needed before generalizing the pattern we found in Iran to other developing countries.

We also found that a disproportionately high number of ROP patients are referred from other regions of the country to capital for the treatment which should promote efforts towards more optimal distribution of ROP care services.

\section{Data Sharing Statement}

The data generated during or/and analyzed during the current study are available from the corresponding author.

\section{Ethics and Consent}

As the research involved human participants, all procedures performed in studies involving human participants were in accordance with the ethical standards of the institutional and/or national research committee and with the 1964 Helsinki declaration and its later amendments or comparable ethical standards. Written informed consent was obtained from all individual participants or their legal guardians at the time of injection.

\section{Author Contributions}

All authors contributed to data analysis, drafting or revising the article, gave final approval of the version to be published, and agree to be accountable for all aspects of the work.

\section{Disclosure}

None of the authors have any proprietary interests or conflicts of interest related to this submission.

\section{References}

1. Gragoudas ES, Adamis AP, Cunningham ET Jr., Feinsod M, Guyer DR, Group VISiONCT. Pegaptanib for neovascular age-related macular degeneration. $N$ Engl J Med. 2004;351 (27):2805-2816. doi:10.1056/NEJMoa042760

2. Rosenfeld PJ, Brown DM, Heier JS, et al. Ranibizumab for neovascular age-related macular degeneration. $N$ Engl J Med. 2006;355 (14):1419-1431. doi:10.1056/NEJMoa054481

3. Epstein DL, Algvere PV, von Wendt G, Seregard S, Kvanta A. Benefit from bevacizumab for macular edema in central retinal vein occlusion: twelve-month results of a prospective, randomized study. Ophthalmology. 2012;119(12):2587-2591. doi:10.1016/j.ophtha.20 12.06 .037

4. Mintz-Hittner HA, Kuffel RR Jr. Intravitreal injection of bevacizumab (avastin) for treatment of stage 3 retinopathy of prematurity in zone I or posterior zone II. Retina. 2008;28(6):831-838. doi:10.1097/ IAE.0b013e318177f934

5. Nguyen QD, Brown DM, Marcus DM, et al. Ranibizumab for diabetic macular edema: results from 2 Phase III randomized trials: RISE and RIDE. Ophthalmology. 2012;119(4):789-801. doi:10.10 16/j.ophtha.2011.12.039

6. Word bank. All Countries and Economies table: 2018; 2017. Available from: https://data.worldbank.org/indicator/SP.POP.TOTL. Accessed December 19, 2017.

7. Rezaei K, Stone T. ASRS global trends in retina; 2014. Available from: https://www.asrs.org/content/documents/2014_global_trends_ comprehensivepostmtg.pdf. Accessed November 20, 2014.

8. Vorum H, Olesen TK, Zinck J, Storling Hedegaard M. Real world evidence of use of anti-VEGF therapy in Denmark. Curr Med Res Opin. 2016;32(12):1943-1950. doi:10.1080/03007995.2016.1221803

9. Bavinger JC, Yu Y, VanderBeek BL. Comparative risk of endophthalmitis after intravitreal injection with bevacizumab, aflibercept, and ranibizumab. Retina. 2019;39(10):2004-2011. doi:10.1097/IAE.0000 000000002351

10. Shuaib A, Hassan S. Indications for intravitreal anti vascular endothelial growth factor in Kano, North Western, Nigeria. Int J Res Med Sci. 2016;4:2533-2535. doi:10.18203/2320-6012. ijrms20161891 
11. Pathak R, Pathak A. Study of life style habits on risk of type 2 diabetes. Int J App Basic Med Res. 2012;2(2):92-96.

12. Nathan DM. The diabetes control and complications trial/epidemiology of diabetes interventions and complications study at 30 years: overview. Diabetes Care. 2014;37(1):9-16. doi:10.2337/dc13-2112

13. The statistics portal; 2018. Available from: https://www.statista.com/ statistics/572925/average-age-of-the-population-in-denmark. Accessed April 23, 2020.

14. Azai I Statistical center of Iran. Available from: https://www.amar. org.ir/english/SCI-News-Archive/articleType/ArticleView/articleId/ 2813/Mean-and-median-age-of-the-Iranian-Population-based-on-theresults-of-the-population-and-Housing-Census-the-year- 1395 . Accessed September 2, 2017.
15. Iran birth rate- index mundi; 2017.Available from: https://www.index mundi.com/iran/birth_rate.htm. Accessed 2017.

16. Abdul Aziz AA, Isaac M, Tehrani NN. Using telemedicine to screen for retinopathy of prematurity. CMAJ. 2014;186(13):1012-1014. doi:10.1503/cmaj.131357

17. Roohipoor R, Karkhaneh R, Riazi-Esfahani M, et al. Comparison of intravitreal bevacizumab and laser photocoagulation in the treatment of retinopathy of prematurity. Ophthalmol Retina. 2018;2(9):94 2-948. doi:10.1016/j.oret.2018.01.017

18. Atlas of Tehran metropolis:2017; 2017. Available from: http://atlas. $\mathrm{t}$ e h r a n. i r / e n / P o p u 1 a t i o n M i g a t i o n / Populationdistributioninvariousagegroups.aspx. Accessed September 24, 2017.
Clinical Ophthalmology

\section{Publish your work in this journal}

Clinical Ophthalmology is an international, peer-reviewed journal covering all subspecialties within ophthalmology. Key topics include: Optometry; Visual science; Pharmacology and drug therapy in eye diseases; Basic Sciences; Primary and Secondary eye care; Patient Safety and Quality of Care Improvements. This journal is indexed on PubMed

Submit your manuscript here: https://www.dovepress.com/clinical-ophthalmology-journa

\section{Dovepress}

Central and CAS, and is the official journal of The Society of Clinical Ophthalmology (SCO). The manuscript management system is completely online and includes a very quick and fair peer-review system, which is all easy to use. Visit http://www.dovepress.com/ testimonials.php to read real quotes from published authors. 